\title{
Silver nanoparticles enhance the sensitivity of temozolomide on human glioma cells
}

\author{
Ping Liang ${ }^{1}$, Hongming Shi ${ }^{1}$, Weiguo Zhu ${ }^{1}$, Qunfeng Gui ${ }^{1}$, Ya $X u^{1}$, Jianfeng Meng ${ }^{1}$, \\ Xiaoyuan Guo ${ }^{2}$, Zhuang Gong ${ }^{3}$, Huaqun Chen ${ }^{1}$ \\ ${ }^{1}$ Department of Neurology, Yancheng Hospital Affiliated to Southeast University, Yancheng, 224001, China \\ ${ }^{2}$ Department of Neurology, Zhongda Hospital Affiliated to Southeast University, Nanjing, 210009, China \\ ${ }^{3}$ Department of Nephrology, The First People's Hospital of Yancheng Affiliated to Nantong University, Yancheng, 224001, China \\ Correspondence to: Huaqun Chen, email: drliangping@126.com \\ Keywords: silver nanoparticles (AgNPs), glioma cells, temozolomide (TMZ), chemotherapy
}

Received: August 20, 2016

Accepted: November 07, 2016

Published: November 22, 2016

\section{ABSTRACT}

\begin{abstract}
Glioblastoma multiforme (GBM) continues to be associated with a dismal prognosis despite aggressive treatment. Significant efforts are being made to develop new nanotechnology-based therapeutic and diagnostic agents. Nanoparticles can act directly on cancer cells or as drug carriers to enhance the cancer therapeutic effect. In this study, we investigated the effect of silver nanoparticles (AgNPs) on human glioma U251 cells and its role in the combinational use with Temozolomide (TMZ), an imidazotetrazine derivative of the alkylating agent dacarbazine, against glioma cells. AgNPs were synthesized in the sodium citrate system and the mean size were $26 \mathrm{~nm}$ in diameter. The AgNP particles showed dose-dependent cytotoxicity on U251 cells. They also showed the ability to enhance the drug-sensitivity of TMZ on U251 cells. Our results revealed that AgNPs could have a potential application in enhancing chemotherapy for glioma.
\end{abstract}

\section{INTRODUCTION}

Glioblastoma multiforme (GBM), one of the most common malignant tumors in the central nervous system (CNS), remains a lethal disease with poor prognosis. The treatment of GBM is multimodality in which surgical resection, radiotherapy and chemotherapy play important roles $[1,2]$. Among them, chemotherapy remains the gold standard for patients who can not tolerate surgical procedure or relapse after surgery. However, most glioma cancer eventually develops multidrug resistance (MDR) to current chemotherapeutic drugs that limits the effectiveness of treatment results [3, 4].

To circumvent the cancer drug resistance, strategies have been focus on developing novel therapeutic agents and enhancing cancer drug delivery efficacy. Direct delivery of drug to the tumor site had been proposed and extensively studied. In recent years, scientists were able to synthesize nanoscale, biodegradable and biocompatible drug delivery systems with the advanced nanotechnology. Such accomplishment has made it possible to deliver anticancer drugs using nanoparticles as delivery vehicles [5] .
There are many types of nanocarriers that have been developed to deliver a variety of drugs. The most common nanocarriers are polymeric nanoparticles, solid lipid nanoparticles and liposomes [6-8]. These nanocarriers have shown excellent characteristics as drug delivery system. They reduced non-specific cellular uptake, prolonged the lifetime of drug in systemic circulation. They can control drug release, improve drug targeting ability. Nanocarriers can also be generated as, multidrug encapsulation for treatments that require multi-regimen.

In recent years, a number of chemotherapeutic drugs have been successfully encapsulated in nanoparticles for cancer treatment. The average size of these nanoparticles ranges from 50 to $150 \mathrm{~nm}$. Studies have demonstrated the strength of using nanoparticle delivery system to tackle cancer drug resistance [5]. There are several clinical trials are in progress using nanoparticle-encapsulated anticancer drugs. Some of the nanoparticle encapsulated anticancer drugs are currently available on the market.

Silver nanoparticles (AgNPs) have showed the property of anti-cancers. There were studies show that AgNPs can enter cells by endocytosis [9]. Inside the 
cells, AgNPs localize in the perinuclear region and endolysosomal membrane compartment [10]. Cytotoxicity assay indicated that AgNPs has cytotoxicity whose potency is similar to that of Ag ions [11]. Some researches showed that AgNPs can enter the mitochondria and affect cells' respiration, generating reactive oxygen species (ROS), therefore induced cell apoptosis [12-14]. Besides, AgNPs could cause DNA damage and induce p53 protein expression [15]. Some studies also showed that the function of vascular endothelial growth factor (VEGF) could be affected by AgNPs [16]. These findings confirmed that AgNPs had anti-tumor properties that could be used as an alternative for cancer treatment and for treating angiogenesis-related diseases [17].

Temozolomide (TMZ) is a second-generation imidazotetrazine derivative, which exerts its cytotoxic effects by methylation of specific DNA sites [19]. Although it is effective in the treatment of glioblastoma, drug resistance limits its successful application. It was known that AgNPs have differential sensitivity to normal cells (e.g. human lung fibroblast cells), as compared to cancer cells (e.g. human glioblastoma cells) [18]. In the present study, we investigate the cytotoxicity of AgPNs on glioma cells and explore whether AgNPs can enhance the sensitivity of TMZ against glioma. We demonstrated that the combination of AgNPs and TMZ has potent antiglioma effect and could be explored to developing into novel chemotherapeutic agents for cancer treatment.

\section{RESULTS}

\section{Characteristics of AgNPs}

AgNPs were prepared from the sodium citrate system by using $\mathrm{AgNO}_{3}$ and $\mathrm{NaBH}_{4}$. Under transmission electron microscopy (TEM), AgNPs was found to be heterogeneous spheres with a diameter ranging from 21-32 nm. They were uniformly distributed. The mean diameter of AgNPs was $26 \mathrm{~nm}$ (Figure 1).

\section{Cytotoxicity of AgNPs}

Our previous studies showed that AgNPs have a definite dose-dependent toxicity on cells. We usually regard 1/5 of IC50 as a suitable concentration, because of better biocompatibility and little toxic effect on normal cells. In the preliminary experiments, U251 cells were incubated with different concentrations of AgNPs. We found necrotic and apoptotic cells when AgNPs concentration was greater than $92 \mu \mathrm{mol} / \mathrm{L}$. Most of the cells grow normally when the AgNPs concentration was less than $46 \mu \mathrm{mol} / \mathrm{L}$, the $1 / 5$ of IC50 of AgNPs. Therefore $46 \mu \mathrm{mol} / \mathrm{L}$ of AgNPs was used in the following experiments.

\section{Uptake of AgNPs by U251 cells}

TEM micrographs show that AgNPs distributed inside the cells. AgNPs containing endosomes were mainly seen near the cell membrane. This result indicated that AgNPs might enter the cells through membrane endocytosis. In addition to the nanoparticles-containing endosomes, autophagic cellular vacuoles filled with structures resembling mitochondria and electron dense contents of unknown origin were also observed inside the AgNPs treated cells. A few nanoparticles were seen in the nucleus of the treated cells. (Figure 2).

\section{Colony formation assay}

U251 cells form colony upon culture in Petri dishes. Under the treatment with AgNPs at the concentration of $46 \mu \mathrm{mol} / \mathrm{L}$, the cells' colony forming ability decreased to around $80 \%$ compared to cells without AgNPs treatment. Similarly, TMZ treatment repressed U251 cells' colony forming ability. Treatment of U251 cells with the combination of TMZ and AgNPs, the number of survival colonies significantly decreased (Figure 3). This result indicated that AgNPs could enhance the effect of TMZinduced cell death.

\section{AgNPs induced cell apoptosis and significantly enhanced TMZ sensitivity in inducing cell apoptosis}

The above results showed that TMZ combined with AgNPs significantly decrease the cell survival rate. To understand whether the decreased cell survival was associated with apoptosis, PI and Annexin-VFITC staining was performed and analyzed using flow cytometry. U251 cells were treated with AgNPs, TMZ or combination of both. The results showed although AgNPs or TMZ alone can increase cell apoptosis to certain degree. The apoptosis rate increased much more in cells treated by the combination of AgNPs and TMZ $(P<0.05)$ (Figure 4). These results demonstrated that combination of AgNPs and TMZ further induce apoptosis in cancer cells.

\section{AgNPs induced cell cycle arrest and significantly enhanced TMZ sensitivity in inducing cell cycle arrest}

Analysis of the cell cycle showed that both AgNPs and TMZ alone could induce G2/M arrest. The combinational use of AgNPs with TMZ further induce G2/M arrest (Figure 5). This result indicated that AgNPs can induce cell cycle arrest and enhance the sensitivity of TMA in inducing cell cycle arrest. This result might also explain why more cells could enter apoptosis phase after incubated with AgNPs. 


\section{DISCUSSION}

It was know that AgNPs can induce dose-dependent cytotoxicities that include DNA damage and oxidative stress that can result in cell death. Gliomas are sensitive to agents that cause DNA damage and oxidative stress. AgNPs have differential sensitivity to normal cells (e.g. human lung fibroblast cells), as compared to cancer cells (e.g. human glioblastoma cells) [18]. Studies have shown the cytotoxic effect of AgNPs on a variety of cancer cells, e.g. glioblastoma cells and breast cancer cells [21-25].
AgNPs has been used as a radiosensitizer in the treatment of glioma [25].

In this study, experiments were carried out to study the cytotoxic effect of AgNPs on human glioma cells. Factors that affect the cytotoxicity of AgNPs include the shape and size of particles, the surface charge and capping agent. We found that AgNPs with the size of diameter around $26 \mathrm{~nm}$ can be uptake into cells and released as silver ions, which interfered with the intracellular repair process. Our results indicated that AgNPs have high cytotoxicity against glioma cells at a very low concentration
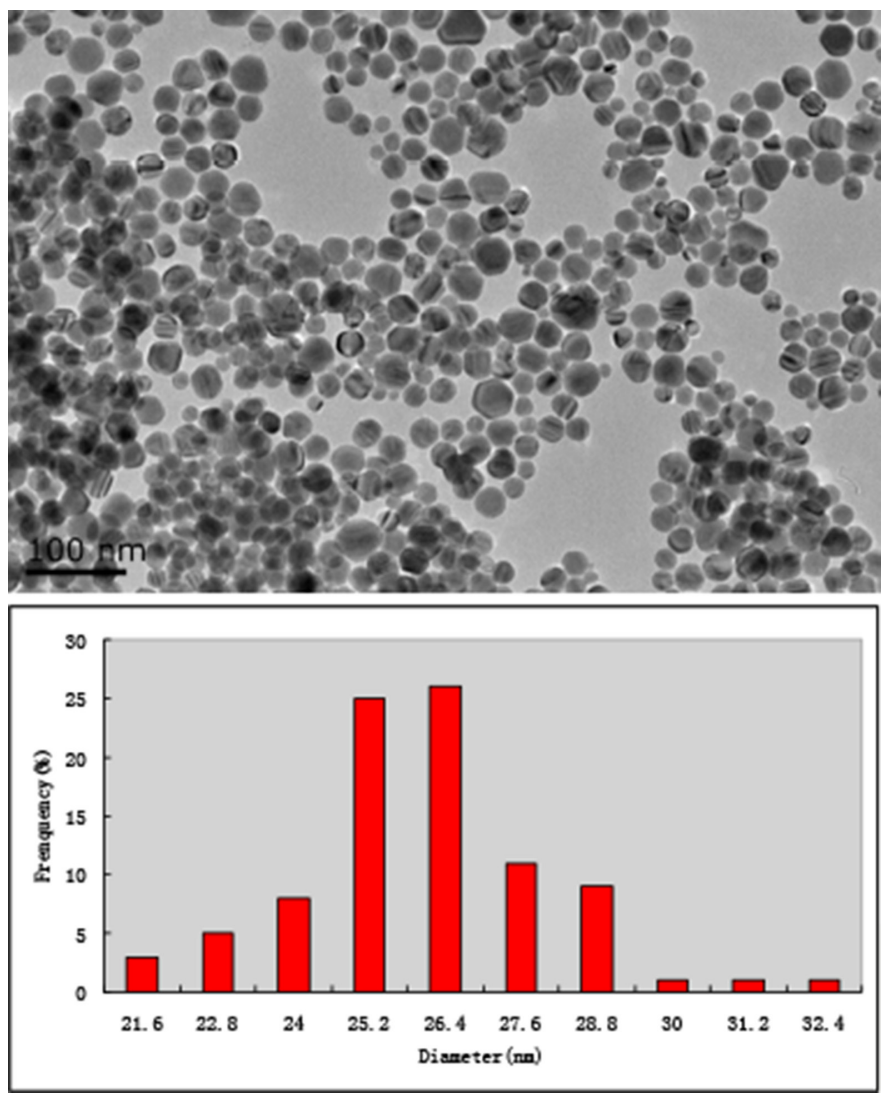

Figure 1: TEM micrograph of AgNPs. AgNPs are heterogeneous spheres (A) with the mean sizes of $26 \mathrm{~nm}$ in diameters (B).
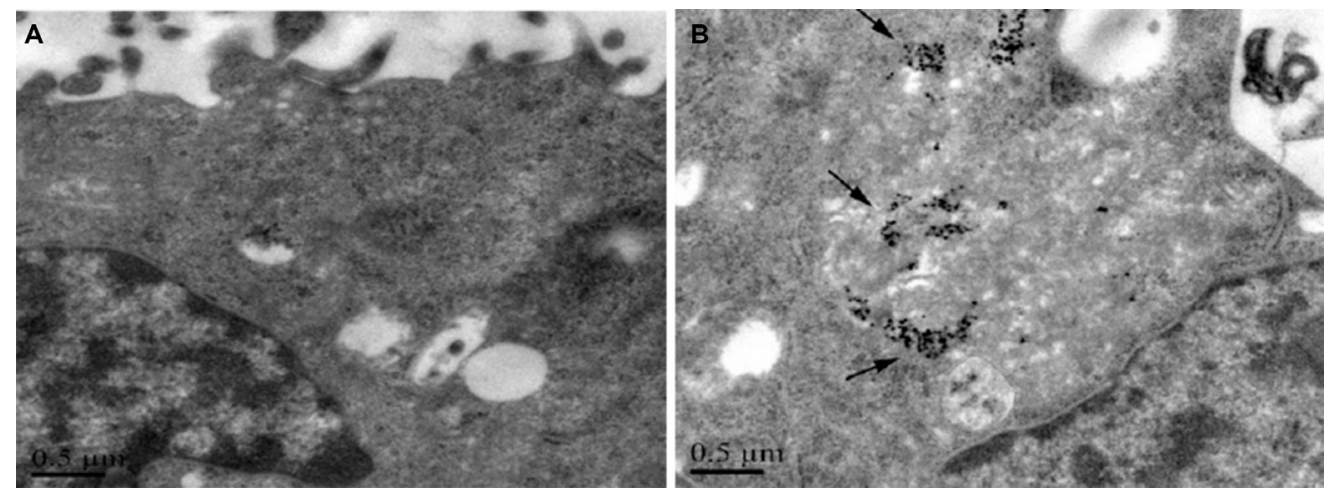

Figure 2: TEM micrograph of U251 cells treated with AgNPs. AgNPs were found distributed inside the cells. (A) untreated, (B) AgNPs treated. 
(46 $\mu \mathrm{mol} / \mathrm{L})$ that have little effect on normal cells. AgNPs induced DNA damage and apoptosis. The cytotoxic effect of AgNPs was concentration-dependent and was enforced when combined use with chemotherapeutic agent TMZ.

As one of the most common and lethal primary malignant tumors in the central nervous system, the prognosis of GBM is very poor. Current regimes for GBM include surgical resection and aggressive treatment with radiotherapy and chemotherapy. Although progress has been made, the results are still not satisfying. In recent years, significant efforts are devoted in the development of nanotechnologybased therapeutic agents. The present study provides a
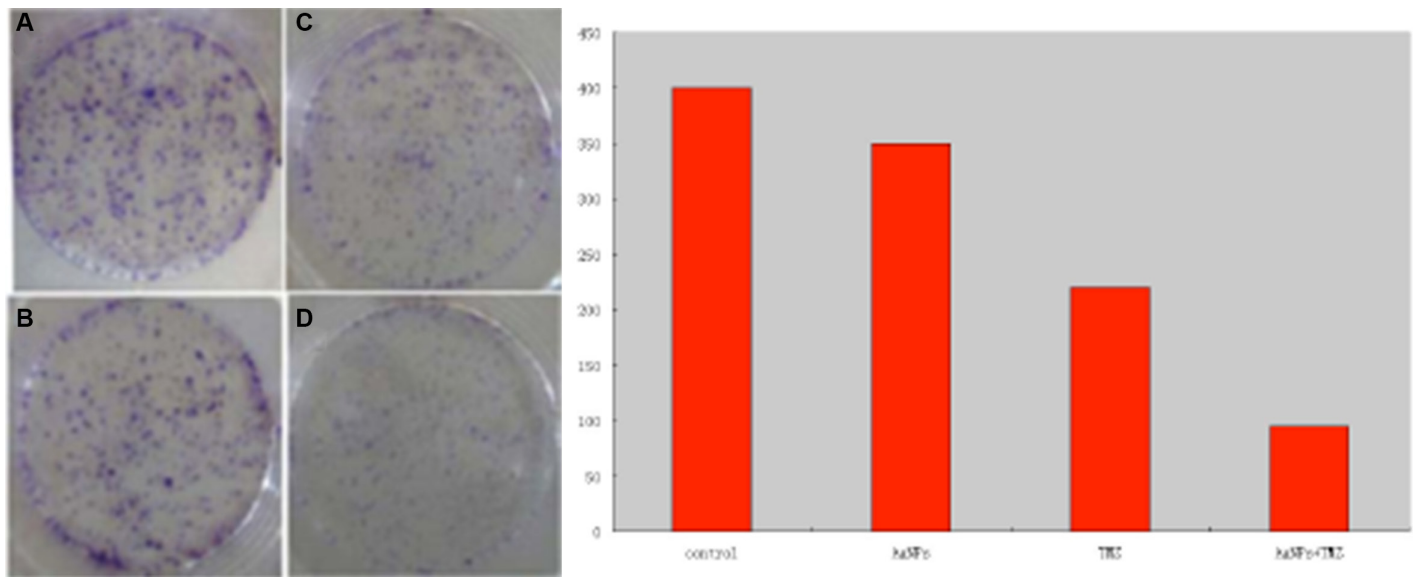

Figure 3: Images of colony-forming assays. (A) control; (B) cells incubated with AgNPs; (C) cells incubated with TMZ; (D) cells incubated with AgNPs + TMZ; (E) Quantitative results of A, B, C, and D.
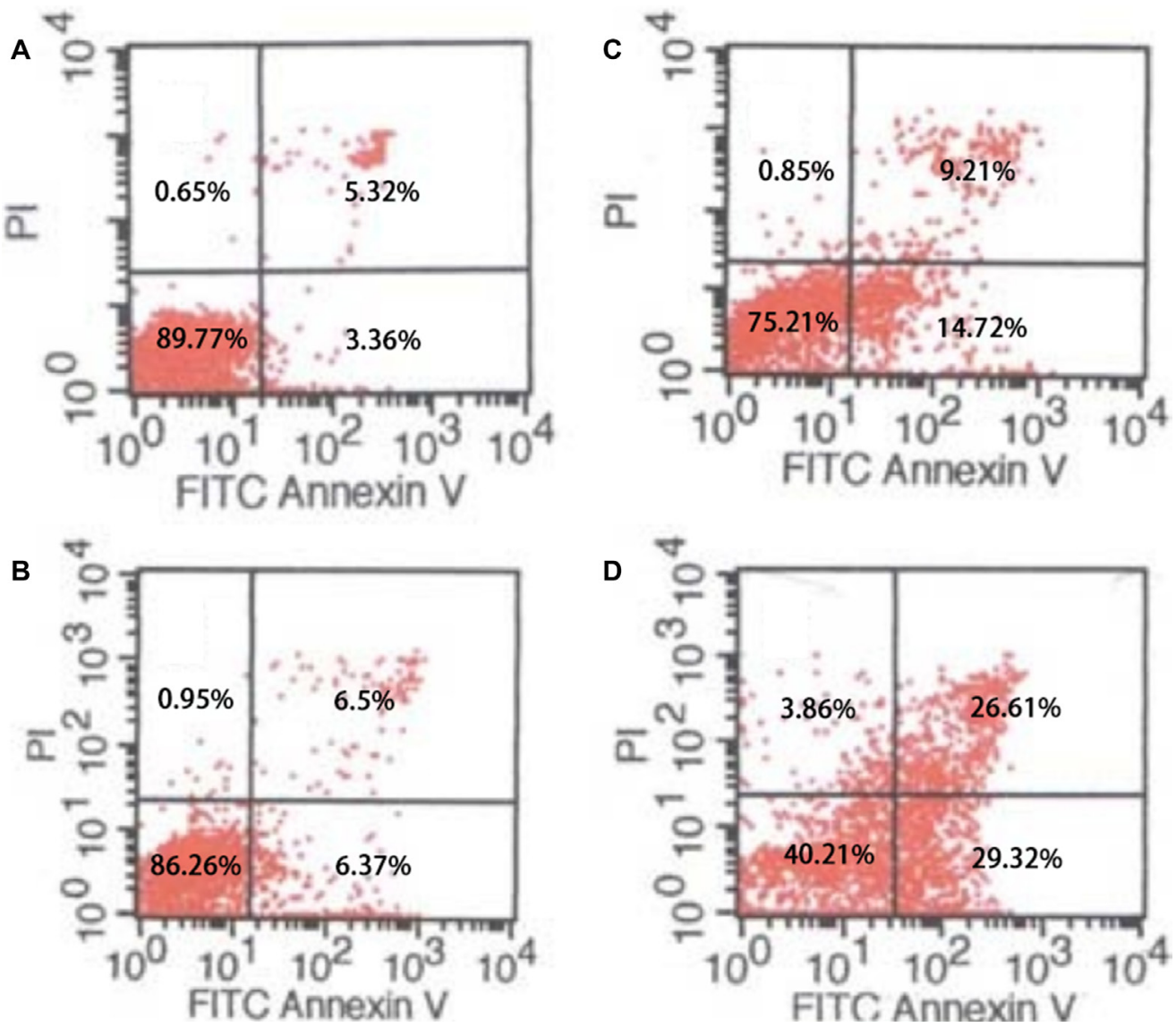

Figure 4: Flow cytometry. Cell apoptosis of U251 cells treated with AgNPs and TMZ. (A) control; (B) cells incubated with AgNPs; (C) cells incubated with TMZ; (D) cells incubated with AgNPs + TMZ. 
rational for using AgNPs to develop into therapeutic agents for GBM. In summary, our studies show that AgNPs have selective cytotoxicity against cancer cells, particularly on glioma cells at doses that are nontoxic to normal cells. It has a dose-enhancement effect in the combinational use with TMZ. These results implicated the potential use of AgNPs as a therapeutic agent for GMB therapy.

\section{MATERIALS AND METHODS}

\section{AgNPs synthesis}

AgNPs was synthesized according to published protocol. Briefly, 0.1 M AgNO3 (0.5 mL) was added into $40 \mathrm{~mL}$ deionized water, and then mixed with freshly prepared $0.02 \mathrm{M} \mathrm{NaBH} 4(1 \mathrm{~mL})$ aqueous solution with vigorous stirring. A solution of $1 \%$ sodium citrate $(10 \mathrm{~mL})$ was added during the reduction. The solution was allowed to stir for an additional $30 \mathrm{sec}$ [20].
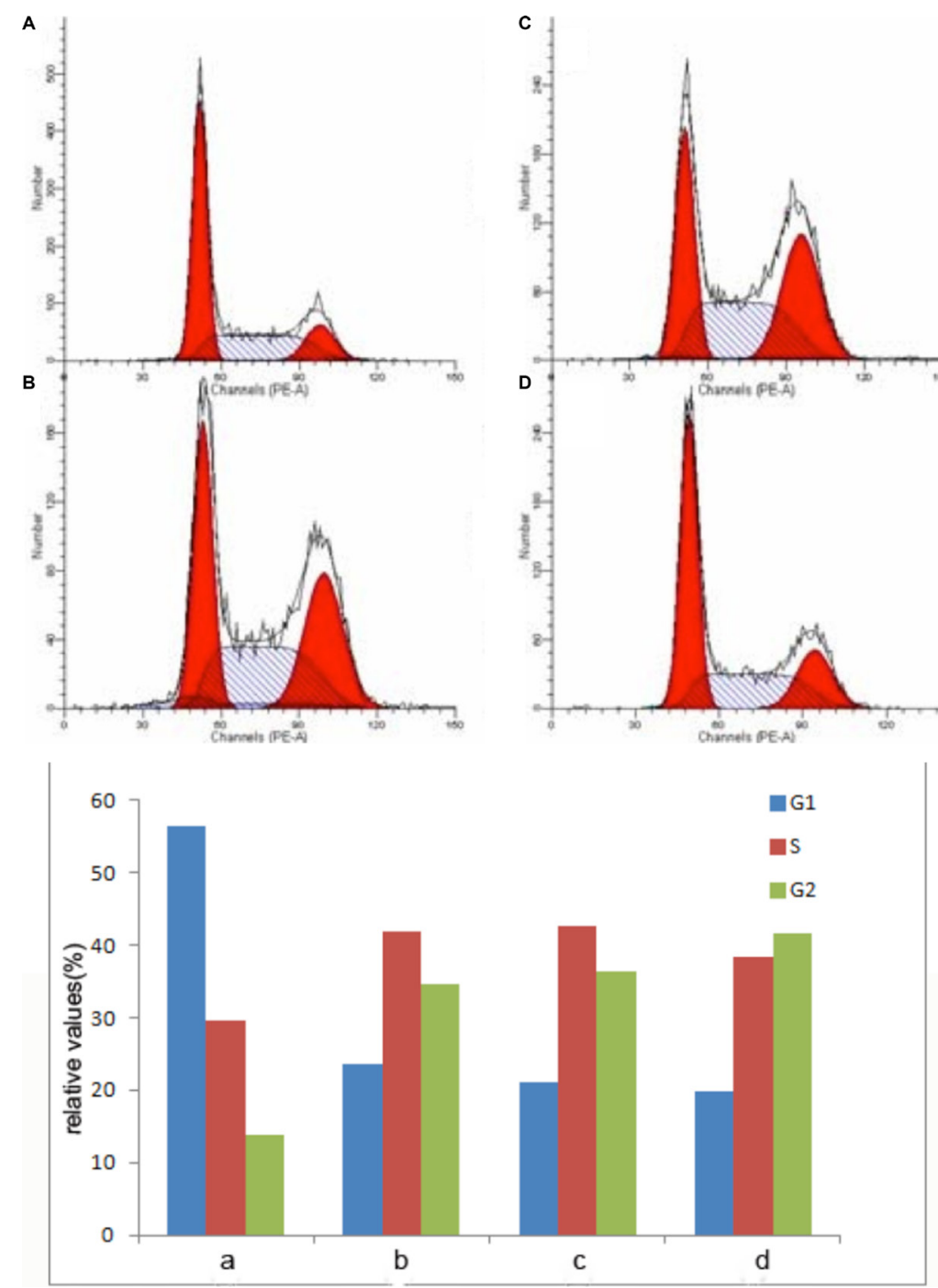

The prepared AgNPs was centrifuged and the supernatant was discarded. AgNPs were then dispersed into Fetal bovine serum (FBS, Sigma Corp. Ltd, Shenzhen, China ) and transferred into Dulbecco's modified eagle's medium (DMEM, Sigma Corp. Ltd) $($ FBS: DMEM = 1:9). The samples received $20 \mathrm{~Gy}$ dose of X-rays irritation for sterilization. The prepared AgNPs were examined by transmission electron microscope (TEM, JEM-2010, JEOL Ltd., Tokyo, Japan).

\section{Cell culture}

The human glioma U251 cells were supplied by Shanghai Institute of Cell Biology and cells were maintained in presence of Glutamine and nonessential amino acids (NEAA), supplemented with 10\% FBS (Sigma Corp. Ltd). Cell cultures were incubated at $37^{\circ} \mathrm{C}$ and equilibrated in 5\% $\mathrm{CO} 2$ and air.

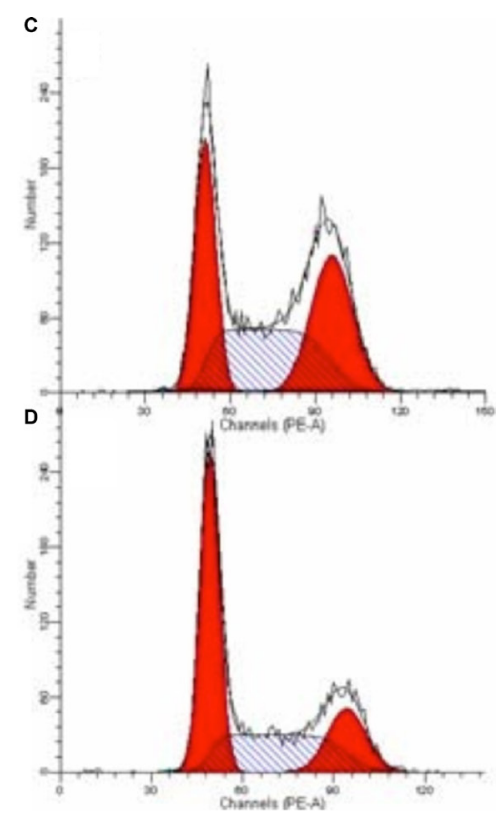

Figure 5: Effect of AgNPs on cell cycle distribution before and after TMZ in U251 cells. (A) control; (B) cells incubated with AgNPs; (C) cells incubated with TMZ; (D) cells incubated with AgNPs + TMZ. 


\section{MTT assay}

U251 cells were transferred into 96-well microplates at a density of $1 \times 10^{3}$ cell/well. At the end of $24 \mathrm{~h}$ culture, cells were cultured with different concentrations of TMZ or AgNPs for another $24 \mathrm{~h}$. After that, the medium was removed. Then $20 \mu \mathrm{l}$ of 3-(4,5-Dimethylthiazol2-yl)-2,5-diphenylterazolium bromide (MTT, Sigma) $(5 \mathrm{mg} / \mathrm{L})$ was added to each well, and placed at $37^{\circ} \mathrm{C}$ for $4 \mathrm{~h}$. Dimethyl sulfoxide (DMSO, $150 \mu \mathrm{l}$ ) was added to each well to dissolve the dark blue crystal products. Absorbance was measured at a wavelength of $570 \mathrm{~nm}$ using a multi-well spectrophotometer (Bio-Rad, Hercules, USA).

\section{Colony formation assay}

The cells were seeded in $1 \times 10^{4}$ per well and cultured in $60 \mathrm{~mm}$ Petri dishes at $37^{\circ} \mathrm{C}$ with $5 \% \mathrm{CO} 2$ in a humidified incubator (three replicates). Twenty-four hours later, AgNPs were added into the medium and the concentration of AgNPs was kept in (1/5 of IC50) $\mu \mathrm{mol} / \mathrm{L}$. Cells were incubated with AgNPs for another $24 \mathrm{~h}$. Then cells were incubated with TMZ with a concentration of $31 \mu \mathrm{mol} / \mathrm{L}$ based on previous MTT assays for another $24 \mathrm{~h}$. After that, cells were washed twice with PBS and re-cultured in the medium containing 10\% FBS for $14 \mathrm{~d}$. Colonies were fixed with methanol, treated with Giemsa stain (Sigma Corp. Ltd), and counted using a microscopy.

\section{Transmission electron microscopy of cells treated with AgNPs}

Cells were treated with AgNPs $46 \mu \mathrm{mol} / \mathrm{L}$ for $24 \mathrm{~h}$, washed well to remove unbound AgNPs. Cells were fixed in $2.5 \%$ gluteraldehyde for $2 \mathrm{~h}$ and washed in phosphate buffer. Post fixation was done in $1 \%$ osmium tetroxide for $1 \mathrm{~h}$. Cells were washed further in phosphate buffer and dehydrated in a series of alcohol for 15 min each $(50 \%$, $70 \%, 80 \%, 95 \%$ and $100 \%)$. Cells were further treated with propylene oxide (30 $\mathrm{min})$, propylene oxide-resin mixture (overnight) and pure resin (48 h). Embedding was done in BEEM capsules using pure Spurrs low viscosity resin at $80^{\circ} \mathrm{C}$ for $48 \mathrm{~h}$. Ultrathin sections were taken using Reichert Jung Ultratome and negatively stained. The stained sections were observed under a transmission electron microscopy (TEM, JEM-2010, JEOL Ltd, Tokyo, Japan)

\section{Apoptosis analysis}

An in situ Apoptosis Detection Kit was used for Annexin V-FITC binding and PI staining (Sigma Corp. Ltd). Following incubation with AgNPs or AgNPs + TMZ for $24 \mathrm{~h}, 2 \times 10^{5}$ cells from each group were harvested and washed with PBS and resuspended in binding buffer (10 mM HEPES, $140 \mathrm{mM}$ sodium chloride, $1.8 \mathrm{mM}$ calcium chloride, $\mathrm{pH}$ 7.4). Then fluorescein-conjugated Annexin
V-FITC $(1 \mu \mathrm{g} / \mathrm{ml})$ and PI reagent $(5 \mu \mathrm{g} / \mathrm{ml})$ were added into cell suspensions. Then the cells were incubated in the dark for $15 \mathrm{~min}$ at room temperature and analyzed immediately by flow cytometry (BD Sciences, San Diego, USA).

\section{Cell cycle analysis}

After incubated with AgNPs for $24 \mathrm{~h}$, cells were incubated with TMZ for $24 \mathrm{~h}$. Then these cells were harvested after treatment and were fixed in $70 \%$ ethanol at $4^{\circ} \mathrm{C}$ for $24 \mathrm{~h}$. Before analysis, cells were washed once in PBS, digested with $500 \mathrm{U} / \mathrm{mL}$ RNase for at least $30 \mathrm{~min}$ at $37^{\circ} \mathrm{C}$ and then stained with PBS containing $50 \mu \mathrm{g} / \mathrm{ml}$ PI for $30 \mathrm{~min}$. Analyses were performed with a flow cytometer (BD Sciences). Cell Cycle distributions were calculated on DNA plots by BD FACS Diva software (Verity Software House).

\section{Statistical analysis}

Sigma plot was used for statistical analysis. Each experiment was performed for at least 3 times. Statistical differences between control and experimental groups were calculated using Student's $t$ test. $P<0.05$ was considered statistically significant.

\section{ACKNOWLEDGMENTS AND FUNDING}

We acknowledge the financial supports of the innovation subject funding of the Health Department of Fujian Province in China (No. 2009-CXB-17).

\section{CONFLICTS OF INTEREST}

Authors declare no conflicts of interest.

\section{REFERENCES}

1. Parney F, Chang SM. Current chemotherapy for glioblastoma. Cancer. 2003; 9:149-156.

2. Stewart LA. Chemotherapy in adult high-grade glioma: a systematic review and meta-analysis of individual patient data from 12 randomised trials. Lancet. 2002; 359:1011-1018.

3. Nagane M, Levitzki A, Gazit A, Webster K. Cavenee, Su Huang HJ, Drug resistance of human glioblastoma cells conferred by a tumor-specific mutant epidermal growth factor receptor through modulation of Bcl-XL and caspase-3-like proteases. Proc Natl Acad Sci USA. 1998; 95:5724-5729.

4. Reardon DA, Egorin MJ, Desjardins A, Vredenburgh JJ, Beumer JH, Lagattuta TF, Gururangan S, Herndon JE, Salvado AJ, Friedman HS. Phase I pharmacokinetic study of the vascularendothelial growth factor receptor tyrosine kinase inhibitor vatalanib (PTK787) plus imatinib and hydroxyurea for malignant glioma. Cancer. 2009; 115:2188-2198. 
5. Peer D, Karp JM, Hong S, Farokhzad OC, Margalit R, Langer R. Nanocarriers as an emerging platform for cancer therapy. Nat Nanotechnol. 2007; 2:751-760.

6. Couvreur P, Vauthier C. Nanotechnology: intelligent design to treat complex disease. Pharmacol Res. 2006; 23: $1417-1450$.

7. Davis ME, Chen ZG, Shin DM. Nanoparticle therapeutics: an emerging treatment modality for cancer. Nat Rev Drug Discov. 2008; 7:771-782.

8. Zhang L, Gu FX, Chan JM, Wang AZ, Langer RS, Farokhzad OC. Nanoparticles in medicine: therapeutic applications and developments. Clin Pharmacol Ther. 2008; 83:761-769.

9. Asharani PV, Hande MP, Valiyaveettil S. Anti-proliferative activity of silver nanoparticles. BMC Cell Biology. 2009; 10:65.

10. Greulich C, Diendorf J, Simon T, Eggeler G, Epple M, Uptake and intracellular distribution of silver nanoparticles in human mesenchymal stem cells. Acta Biomaterialia. $2011 ; 7: 347-354$

11. Kim S, Choi JE, Choi J, Chung KH, Park K, YiJ. Ryu DY, Oxidative stress-dependent toxicity of silver nanoparticles in human hepatoma cells. Toxicology in Vitro. 2009; 23: 1076-1084.

12. Héctor RH, Salma JB, Pedro PMC, Eduardo GE, Humberto T, Mauricio T, Saber MH, Syed FA, Carmen G, Effects of 45-nm silver nanoparticles on coronary endothelial cells and isolated rat aortic rings. Toxicology Lett. 2009; 191:305-313.

13. Hsin YH, Chen CF, Huang S, Shih TS, Lai PS, Chueh PJ, The apoptotic effect of nanosilver is mediated by a ROS- and JNKdependent mechanism involving the mitochondrial pathway in NIH3T3 cells. Toxicology Lett. 2008; 179:130-139.

14. Sanpui P, Chattopadhyay A, Ghosh SS, Induction of apoptosis in cancer cells at low silver nanoparticle concentrations using chitosan nanocarrier. ACS Appl Mater Interfaces. 2011; 3:218-228.

15. Ahamed M, Karns M, Goodson M, Rowe J, Hussain SM, Schlager JJ, Hong Y. DNA damage response to different surface chemistry of silver nanoparticles in mammalian cells.Toxicology and Applied Pharmacology. 2008; 233:404-410.
16. Kalishwaralal K, Banumathi E, Ram KPS, Deepak V, Muniyandi J, Eom SH, Gurunathan S. Silver nanoparticles inhibit VEGF induced cell proliferation and migration in bovine retinal endothelial cells, Colloids and Surfaces B: Biointerfaces. 2009; 73:51-57.

17. Sriram MI, Kanth SBM, Kalishwaralal K, Gurunathan S, Antitumor activity of silver nanoparticles in Dalton's lymphoma ascites tumor model. Inter J Nanomedicine. 2010; 5:753-762.

18. AshaRani PV, Mun GLK, Hande MP, Valiyaveettil S. Cytotoxicity and genotoxicity of silver nanoparticles in human cells. ACS Nano. 2009; 3:279-290.

19. Hegi ME, Diserens AC, Gorlia T, Hamou MF, de Tribolet N, Weller M, Kros JM, Hainfellner JA, Mason W, Mariani L, Bromberg JE, Hau P, Mirimanoff RO, et al. MGMT gene silencing and benefit from temozolomide in glioblastoma. N Engl J Med. 2005; 352:997-1003.

20. Lee PC, Meisel D, Adsorption and surface-enhanced Raman of dyes on silver and gold sols. J Phys Chem. 1982; 86:3391-3395.

21. Jeyaraj M, Sathishkumar G, Sivanandhan G. Biogenic silver nanoparticles for cancer treatment: an experimental report. Colloids Surf B Biointerfaces. 2013; 106:86-92.

22. Liu JH, Zhao YX, Guo QQ, Wang Z, Wang H, Yang Y, Huang Y, et al. TAT-modified nanosilver for combating multidrug-resistant cancer. Biomaterials. 2012; 33: 6155-6161.

23. Locatelli E, Naddaka M, Uboldi C, Loudos G, Fragogeorgi E, Molinari V, Pucci A, Tsotakos T, Psimadas D, Ponti J, Franchini MC, et al. Targeted delivery of silver nanoparticles and alisertib: in vitro and in vivo synergistic effect against glioblastoma. Nanomedicine (Lond) 2014; 9:839-849.

24. Sharma S, Chockalingam S, Sanpui P, Chattopadhyay A, Ghosh SS. Silver nanoparticles impregnated alginatechitosan-blended nanocarrier induces apoptosis in human glioblastoma cells. Adv Healthc Mater. 2014; 3:106-114.

25. Liu PD, Huang ZH, Chen ZW, Xu R, Wu H, Zang F, Wang C, Gu N, et al. Silver nanoparticles: a novel radiation sensitizer for glioma? Nanoscale. 2013; 5:11829-11836. 